\title{
Factors Associated with Withdrawal Time in European Colonoscopy Practice: Findings of the European Colonoscopy Quality Investigation (ECQI) Group
}

\author{
Cristiano Spada 1,2,*, Anastasios Koulaouzidis ${ }^{3,4,5,6}{ }^{10}$, Cesare Hassan ${ }^{7}$, Pedro Amaro ${ }^{8}$, Anurag Agrawal ${ }^{9}$, \\ Lene Brink ${ }^{10}$, Wolfgang Fischbach ${ }^{11}$, Matthias Hünger ${ }^{12}$, Rodrigo Jover ${ }^{13}$, Urpo Kinnunen ${ }^{14}$ (i), Akiko Ono ${ }^{15}$, \\ Árpád Patai ${ }^{16}$, Silvia Pecere ${ }^{17}$ D , Lucio Petruzziello ${ }^{17}$, Jürgen F. Riemann 18,19, Harry Staines ${ }^{20}$, Ann L. Stringer ${ }^{21}$, \\ Ervin Toth ${ }^{22}$, Giulio Antonelli ${ }^{23,24}$ and Lorenzo Fuccio ${ }^{25}$ on behalf of the ECQI Group
}

Citation: Spada, C.; Koulaouzidis, A.; Hassan, C.; Amaro, P.; Agrawal, A.; Brink, L.; Fischbach, W.; Hünger, M.; Jover, R.; Kinnunen, U.; et al. Factors Associated with Withdrawal Time in European Colonoscopy Practice: Findings of the European Colonoscopy Quality Investigation (ECQI) Group. Diagnostics 2022, 12, 503. https://doi.org/10.3390/ diagnostics 12020503

Academic Editor: Elina A. Genina

Received: 14 January 2022

Accepted: 3 February 2022

Published: 15 February 2022

Publisher's Note: MDPI stays neutral with regard to jurisdictional claims in published maps and institutional affiliations.

Copyright: (C) 2022 by the authors. Licensee MDPI, Basel, Switzerland. This article is an open access article distributed under the terms and conditions of the Creative Commons Attribution (CC BY) license (https:// creativecommons.org/licenses/by/ $4.0 /)$.
1 Digestive Endoscopy Unit and Gastroenterology, Fondazione Poliambulanza, 25124 Brescia, Italy

Digestive Endoscopy Unit, Università Cattolica del Sacro Cuore, 00168 Rome, Italy

Department of Medicine, OUH Svendborg Sygehus, 5700 Svendborg, Denmark; akoulaouzidis@hotmail.com

Department of Clinical Research, University of Southern Denmark (SDU), 5000 Odense, Denmark

Surgical Research Unit, OUH, 5000 Odense, Denmark

6 Department of Social Medicine and Public Health, Pomeranian Medical University, 70-204 Szczecin, Poland

7 Endoscopy Unit, IRCCS Humanitas Clinical and Research Center, 20089 Milan, Italy; cesareh@hotmail.com

8 Gastroenterology Department, Centro Hospitalar e Universitário de Coimbra, 3000-075 Coimbra, Portugal; pedro.amaro1967@gmail.com

9 Gastroenterology, Doncaster Royal Infirmary, Doncaster DN2 5LT, UK; anurag.agrawal1@nhs.net

10 Gastro Unit, Division of Endoscopy, Herlev and Gentofte Hospital, Copenhagen University, 2730 Herlev, Denmark; lene.brink@regionh.dk

11 Gastroenterologie und Innere Medizin, 63739 Aschaffenburg, Germany; wuk.fischbach@gmail.com

12 Independent Researcher for Internal Medicine, 97070 Würzburg, Germany; mhuenger@gmx.net

13 Instituto de Investigación Sanitaria ISABIAL—Servicio de Medicina Digestiva,

Hospital General Universitario de Alicante, 03010 Alicante, Spain; rodrigojover@gmail.com

14 Department of Gastroenterology, Tampere University Hospital, 33521 Tampere, Finland; urpo.kinnunen@pshp.fi

15 Department of Gastroenterology, Hospital Clínico Universitario Virgen de la Arrixaca, El Palmar, 30120 Murcia, Spain; ono.akiko@gmail.com

16 Department of Gastroenterology and Medicine, Markusovszky University Teaching Hospital, 9700 Szombathely, Hungary; pataiarpaddr@gmail.com

17 Digestive Endoscopy Unit, Fondazione Policlinico Universitario A. Gemelli IRCCS, 00168 Rome, Italy; silvia.pecere@gmail.com (S.P.); luciopetruzziello@gmail.com (L.P.)

18 Department of Medicine C, Klinikum Ludwigshafen, 67063 Ludwigshafen, Germany; riemannj@garps.de

19 LebensBlicke Foundation, 67063 Ludwigshafen, Germany

20 Sigma Statistical Services Ltd., Saint Andrews KY16 0BD, UK; harry.j.staines@gmail.com

21 ECQI Secretariat, Buckinghamshire HP17 8ET, UK; ann.stringer@aspenmedicalmedia.com

22 Department of Gastroenterology, Skåne University Hospital, Lund University, 20502 Malmö, Sweden; ervin.toth@med.lu.se

23 Department of Anatomical, Histological, Forensic Medicine and Orthopedics Sciences,

"Sapienza" University of Rome, 00185 Rome, Italy; giulio.antonelli@gmail.com

24 Gastroenterology and Digestive Endoscopy Unit, Ospedale dei Castelli, Ariccia, 00040 Rome, Italy

25 Gastroenterology Unit, Department of Medical and Surgical Sciences, S. Orsola-Malpighi Hospital, 40138 Bologna, Italy; lorenzofuccio@gmail.com

* Correspondence: cristianospada@gmail.com 
1150 qualifying colonoscopies, the mean WT was $7.8 \mathrm{~min}$. Stepwise analysis, including 587 procedures where all inputs were known, found that the variables most associated with mean WT were a previous total colonoscopy in the last five years $(p=0.0011)$ and the time of day the colonoscopy was performed $(p=0.0192)$. The main factor associated with a WT $<6 \mathrm{~min}$ was the time of day that a colonoscopy was performed. Use of sedation was the main factor associated with a higher proportion of WT $>10 \mathrm{~min}$, along with a previous colonoscopy. Conclusions: On average, the sample of European practice captured by the ECQI survey met the minimum standard set by the ESGE. However, there was variation and potential for improvement.

Keywords: colonoscopy; colonoscopy standards; withdrawal time; quality measures

\section{Introduction}

The adenoma detection rate (ADR) is a validated quality measure that colonoscopists should constantly seek to improve. While ADR may be considered the primary quality indicator, it is a function of other quality measures, such as cecal intubation rate, withdrawal time (WT), and quality of bowel preparation. Colonoscope WT is considered a surrogate measure for the time spent investigating the mucosa to identify pathology [1].

The European Colonoscopy Quality Investigation (ECQI) Group (www.ecqigroup org (accessed on 13 January 2022) comprises specialists and advisors and aims to raise awareness of the need for improvement in colonoscopy standards across Europe. The ECQI is a collaborative working party seeking cooperation and input from all stakeholders in the field of colonoscopy. The ECQI's aim is not to create new quality criteria, but rather to document dissemination of the European Society of Gastrointestinal Endoscopy (ESGE) guidelines and record their implementation in daily practice throughout Europe [2]. At the inaugural meeting of the ECQI Group, convened in 2013, to discuss quality in colonoscopy, the Group recommended devising a clinical practice questionnaire to evaluate the current practice of endoscopists across Europe. The main findings from this questionnaire have already been published [2].

In 2017, the ESGE published performance measures for lower gastrointestinal endoscopy [1]. The ESGE recommend that endoscopy services across Europe adopt the key performance measures for measurement and evaluation in daily practice at a center and endoscopist level. As a secondary analysis, we analyzed a sample of procedures conducted across Europe, between June 2016 and April 2018, in order to evaluate the current achievement of WT standards, as defined by the ESGE. We also analyzed data collected on procedures with regard to factors associated with WT, in the hope of establishing areas that could lead to an improvement in quality [1].

\section{Methods}

\subsection{Questionnaire Development}

The questionnaire was developed with consideration of the ESGE quality standards [3]. An iterative process was used to hone the questionnaire, ensuring that the time to complete the form was not too onerous [4]. This analysis uses the version finalized in 2016 and available for completion from 2 June 2016 (see Supplementary Materials).

\subsection{Recruitment}

Participation was open to all Europe-based colonoscopists via web-based registration on the ECQI Group website. Awareness of the questionnaire came from abstracts, posters, presentations at national and international congresses, and individual communications from ECQI Group members. Interested participants applied via the ECQI Group website or to the ECQI Group Secretariat. Following verification, log-in access to the web-based questionnaire site was provided by email. 


\subsection{Ethics}

This survey was performed with anonymized data, collected during regular clinical care, representing an audit of routine endoscopic practice against quality standards. Accordingly, participating physicians were encouraged to follow relevant local regulations. Furthermore, contemporary (pre-General Data Protection Regulation, GDPR, 2018) guidance was followed at the time of data collection.

\subsection{Dataset}

Form completions from 2 June 2016 to 30 April 2018 were included in this analysis.

\subsection{Withdrawal Time}

The ESGE define the WT as time spent on withdrawal of the endoscope from the cecum to the anal canal and inspection of the entire bowel mucosa at negative (no biopsy or therapy) screening or diagnostic colonoscopy [1]. We identified screening and diagnostic colonoscopies in our dataset using the reason for procedure question. 'Signs and symptoms' was classified as diagnosis, and the responses, 'Screening due to familial risk', 'Screening without pre-screening test' and 'Following positive screening test' were classified as screening. The 'Other' response free-text section was reviewed and responses re-classified as the above, as appropriate. All responses that were neither diagnosis nor screening were excluded from this analysis group. We used the 'Retraction time' recorded in colonoscopies reporting the cecum as the intended endpoint, that reported reaching the intended endpoint, and did not report any endoscopic intervention, in order to provide a mean WT.

As well as mean WT, analysis was performed using the cut-off points of 6 min and $10 \mathrm{~min}$, as per the ESGE recommendations for minimum and target mean WT, respectively [1]. Descriptive statistics were provided for each variable category, and one-way analysis of variance was used to test for equality of mean across variable categories. WT $<6 \mathrm{~min}$ and $\mathrm{WT}>10 \mathrm{~min}$ were treated as separate binary responses.

\subsection{Statistical Analysis}

To preserve anonymity, only the patient's year of birth was recorded. Age at the date of the procedure was derived assuming the date of birth was 30 June. Quantitative variables are presented as mean \pm standard deviation (SD). Binary responses are presented as frequency and percentage.

Univariate binary logistic regression models were used to determine the association of individual variables with an endpoint using pre-defined categories. For selected analyses involving pairs of variables, the interaction term was added to the model, in addition to the two main effects. Stepwise multivariable logistic regression analysis was conducted to determine the most influential associated factors after adjusting for the other pre-specified variables. Stepwise analysis was performed on the following variables: age < 50; gender; BMI categories; inpatient status; reason for procedure; time of colonoscopy; previous total colonoscopy in the last five years; Boston Bowel Preparation Score (BBPS) of adequate [5]; and sedation used. A variable was included in the stepwise model if the $p$ value for entering the model was $<0.05$, and removed if the $p$ value was $>0.10$. Such analysis was restricted to the set of procedures for which all the pre-specified variables are known.

No adjustment for multiplicity was made with a $p$ value $<0.05$ used to define significance. All analyses were performed using the statistical software package SAS version 9.4. (Cary, NC, USA). As sensitivity analyses, missing data were imputed using multiple imputation by chained equations (MICE) [6]. A total of 100 multiple imputation (MI) datasets were created imputing missing data for individual variables using the other potential variables selected for the stepwise model. Analyses were conducted separately for each MI dataset, and the results for effects pooled using Rubin's method [7]. The mean $p$ value for the overall model was also calculated. 


\section{Results}

A total of 6445 completed procedure forms from 12 countries were considered for inclusion in analysis. Forms were received from 25 academic hospitals $(\mathrm{n}=2270), 14$ hospitals $(n=1235), 8$ private institutions $(n=2657), 3$ group practices $(n=160)$, and 1 other center $(n=123)$. There were 1150 procedures that met the criteria for the WT analysis (see Figure 1). These were divided between 41 institutions, with a median of 10 procedures per institution (range 1-154).

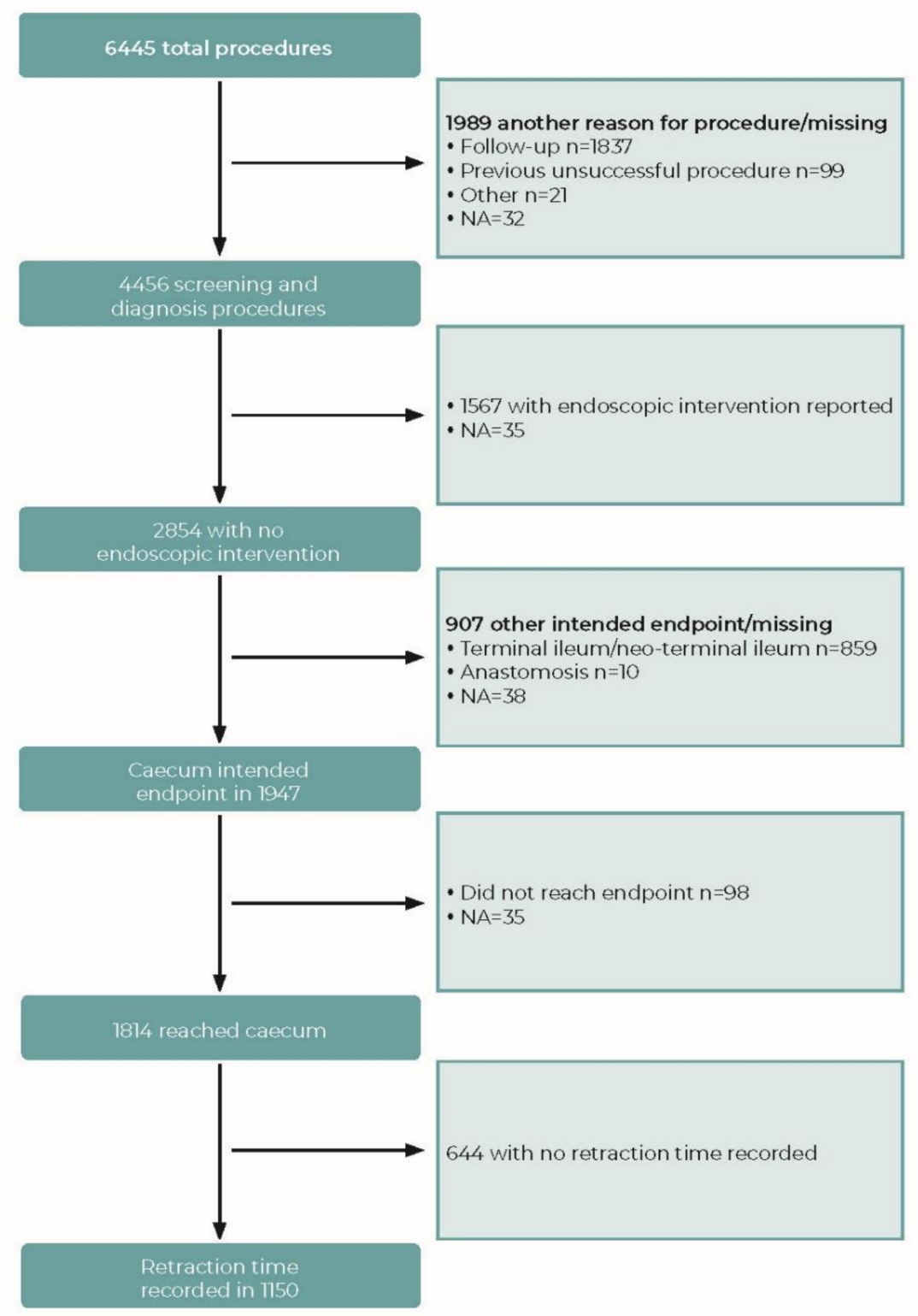

Figure 1. Flowchart indicating data inclusion/exclusion for analysis of withdrawal time (WT). NA: not answered.

\subsection{Withdrawal Time}

The overall mean WT was $7.8 \pm 3.1 \mathrm{~min}$, and the median WT was $7 \mathrm{~min}$. The proportion of patients receiving a WT less than $6 \mathrm{~min}$ was $13.0 \%$ (150/1150), and the proportion with a WT greater than 10 min was 10.8\% (124/1150). Stepwise analysis, including 587 procedures where all inputs were known, found that the variables most associated with mean WT were a previous total colonoscopy in the last five years (yes $8.9 \pm 3.9$ vs. no $7.8 \pm 3.2$; $p=0.0011)$ and the time of day the colonoscopy was performed $(8.3 \pm 2.7,7.9 \pm 4.0$ and 
$6.6 \pm 2.2$, respectively, for patients whose colonoscopy was performed between 07:00-11:59, 12:00-17:59, and 18:00-19:59; $p=0.0192)$. Following MI, mean $p$ values for variables remained broadly similar. with the notable exception of the time of day that the colonoscopy was performed, which lost significance. Stepwise analysis, performed on the 100 MICE datasets, showed adequate cleansing, sedation, patient type, and reason for procedure were included in each of the 100 models. The time of day was included in 76 models, and total colonoscopy within the last five years was included in 10 models.

WT was not influenced by either age or BMI (data not shown). The factors significantly associated with mean WT are shown in Table 1. Gender had no significant influence on mean WT or the proportion with a WT over 10 min; however, men were significantly less likely to receive a WT of less than 6 min (10.3\% vs. $14.9 \%$; OR $0.657,95 \%$ CI $0.456,0.944$; $p=0.023)$. The only other factor with a significant association to the proportion of patients with a WT less than 6 min was the time of day the colonoscopy was performed (Figure 2), which was the only associated factor in the stepwise analysis. In the stepwise analysis, the proportion of patients with a withdrawal time less than 6 min was $12.3 \%, 19.7 \%$, and $35.7 \%$, respectively, for a colonoscopy performed between 07:00-11:59, 12:00-17:59, and 18:00-19:59. The OR (vs. colonoscopies between 07:00 and 11:59) were 1.751 (95\%CI 1.097, 2.796; $p=0.0189)$ and 3.968 (95\%CI 1.925, 8.181; $p=0.0002)$, respectively, for colonoscopies performed between 12:00-17:59 and 18:00-19:59. Following MI, the mean $p$ value for the time of day increased to $p=0.002$, while all other variables remained non-significant, except gender, which remained at $p=0.023$, as there were no missing data for this variable. Stepwise analysis following MI retained the time of day, but gender was also included in all 100 models.

Table 1. Influence of variables on mean withdrawal time (minutes).

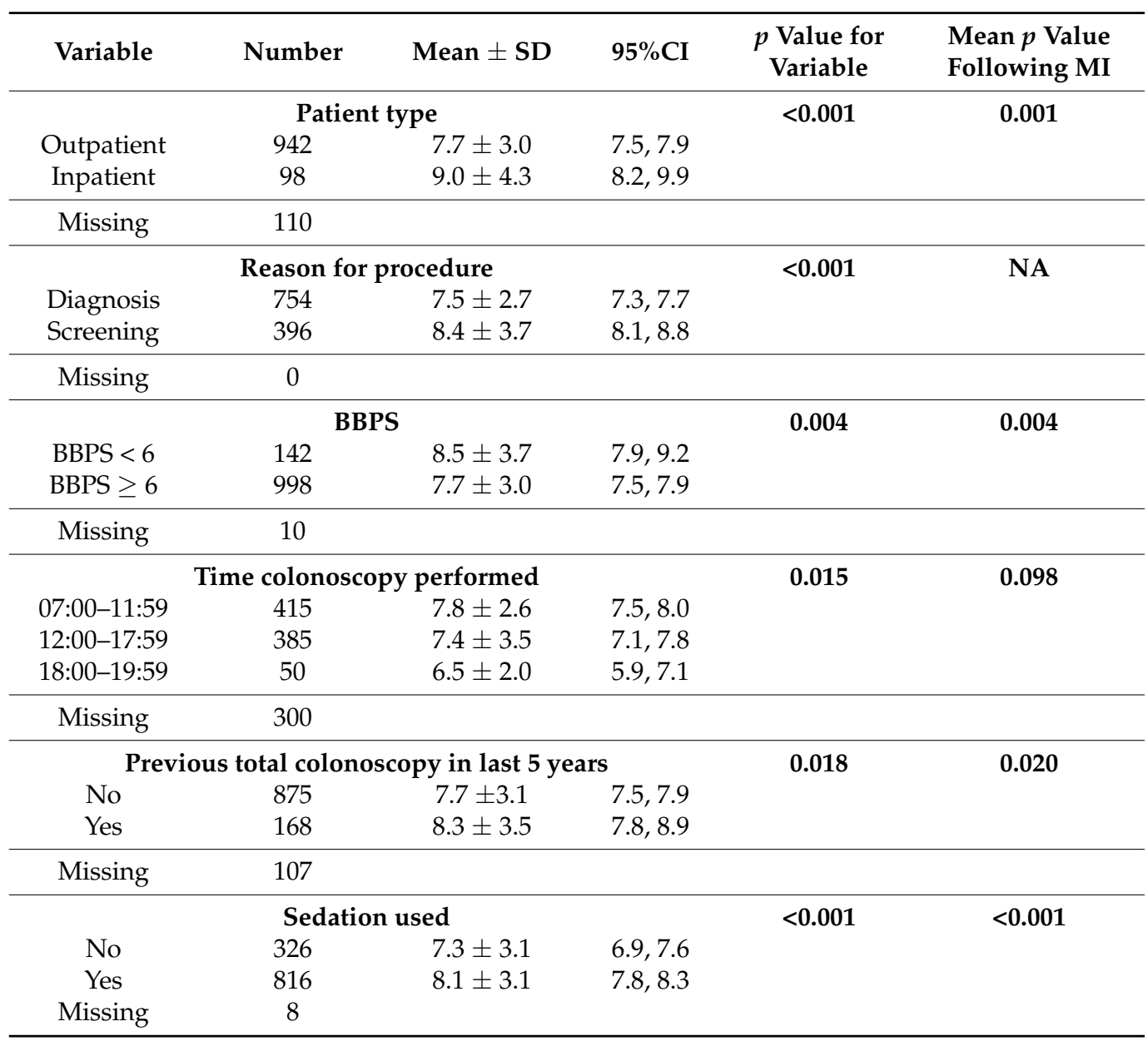




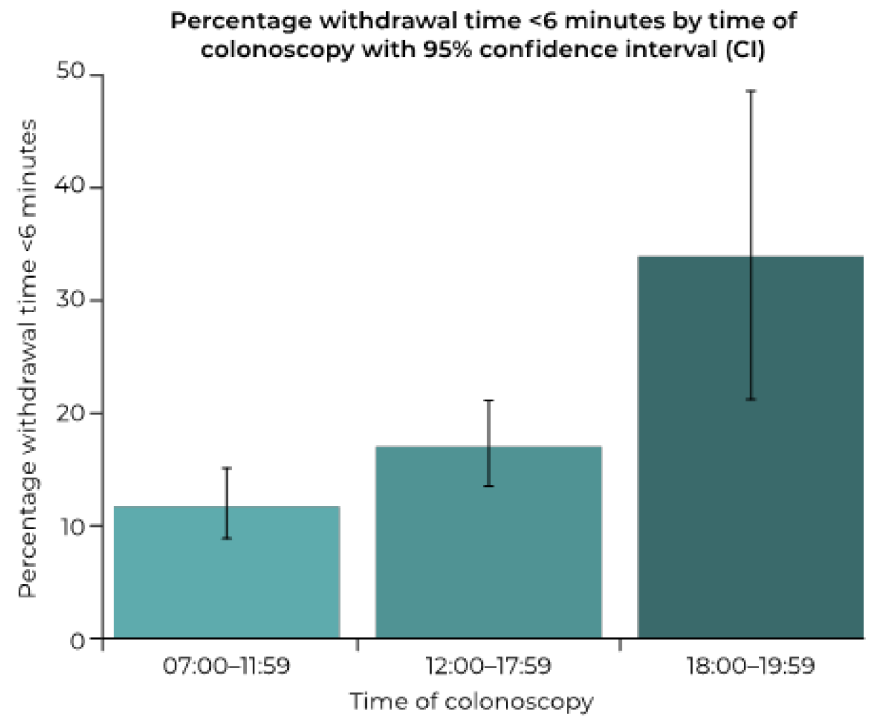

\begin{tabular}{|l|l|l|l|}
\hline & $\begin{array}{l}\text { Proportion with } \\
\text { withdrawal time } \\
<6 \text { minutes (\%) }\end{array}$ & $\begin{array}{l}\text { Odds ratio } \\
(95 \% \mathrm{CI})\end{array}$ & P value \\
\hline $\begin{array}{l}\text { Time } \\
\text { colonoscopy } \\
\text { performed }\end{array}$ & & & $<0.001$ \\
\hline $07: 00-11: 59$ & $49 / 415(11.8)$ & Reference & \\
\hline $12: 00-17: 59$ & $66 / 385(17.1)$ & $1.545(1.037,2.303)$ & 0.032 \\
\hline $18: 00-19: 59$ & $17 / 50(34.0)$ & $3.848(1.995,7.421)$ & $<0,001$ \\
\hline
\end{tabular}

Figure 2. Influence of the time of day that a procedure is performed upon the proportion of procedures with a withdrawal time under 6 min.

Stepwise analysis of the variables associated with the proportion of patients receiving a WT greater than $10 \mathrm{~min}$ showed that sedation was the primary factor (yes $14.3 \%$ vs. no $7.3 \%$; OR $2.115,95 \%$ CI 1.083, 4.134; $p=0.0284$ ), followed by a previous total colonoscopy in the last five years (yes $18.4 \%$ vs. no $11.2 \%$; OR $1.805,95 \%$ CI 1.018, 3.201; $p=0.0478$ ). The influence of individual variables is shown in Table 2. Following MI, sedation use remained in all 100 stepwise models; however, it was joined in all models by patient type, reason for procedure, and adequate cleansing. Total colonoscopy in the previous five years only appeared in one of the $100 \mathrm{MI}$ models.

Table 2. Influence of individual variables on the proportion of patients with a withdrawal time greater than $10 \mathrm{~min}$.

\begin{tabular}{|c|c|c|c|c|c|}
\hline Variable & $\begin{array}{l}\text { Proportion with Withdrawal } \\
\text { Time }>10 \mathrm{~min}(\%)\end{array}$ & $\begin{array}{l}\text { Odds Ratio } \\
(95 \% \mathrm{CI})\end{array}$ & $p$ Value & $\begin{array}{l}p \text { Value for } \\
\text { Variable }\end{array}$ & $\begin{array}{l}\text { Mean } p \text { Value } \\
\text { Following MI }\end{array}$ \\
\hline \multicolumn{4}{|c|}{ Patient type } & \multirow[t]{3}{*}{0.005} & \multirow[t]{3}{*}{0.021} \\
\hline Outpatient & $94 / 942(10.0)$ & Reference & & & \\
\hline Inpatient & 19/98 (19.4) & $2.170(1.259,3.739)$ & 0.005 & & \\
\hline \multicolumn{4}{|l|}{ Missing } & & \\
\hline \multicolumn{4}{|c|}{ Reason for procedure } & $<0.001$ & NA \\
\hline Diagnosis & $63 / 754(8.4)$ & Reference & & & \\
\hline Screening & $61 / 396(15.4)$ & $1.997(1.372,2.907)$ & $<0.001$ & & \\
\hline Missing & 0 & & & & \\
\hline
\end{tabular}


Table 2. Cont.

\begin{tabular}{|c|c|c|c|c|c|}
\hline Variable & $\begin{array}{c}\text { Proportion with Withdrawal } \\
\text { Time }>10 \mathrm{~min}(\%)\end{array}$ & $\begin{array}{l}\text { Odds Ratio } \\
(95 \% \mathrm{CI})\end{array}$ & $p$ Value & $\begin{array}{l}p \text { Value for } \\
\text { Variable }\end{array}$ & $\begin{array}{l}\text { Mean } p \text { Value } \\
\text { Following MI }\end{array}$ \\
\hline \multicolumn{4}{|c|}{ BBPS } & 0.007 & 0.007 \\
\hline BBPS $<6$ & $25 / 142(17.6)$ & Reference & & & \\
\hline $\mathrm{BBPS} \geq 6$ & $99 / 998(9.9)$ & $0.515(0.319,0.832)$ & 0.007 & & \\
\hline Missing & 10 & & & & \\
\hline \multicolumn{4}{|c|}{ Time colonoscopy performed } & 0.479 & 0.561 \\
\hline 07:00-11:59 & $44 / 415(10.6)$ & Reference & & & \\
\hline $12: 00-17: 59$ & $34 / 385(8.8)$ & $0.817(0.510,1.308)$ & 0.399 & & \\
\hline 18:00-19:59 & $3 / 50(6.0)$ & $0.538(0.161,1.802)$ & 0.315 & & \\
\hline Missing & 300 & & & & \\
\hline \multicolumn{4}{|c|}{ Previous total colonoscopy in last five years } & 0.083 & 0.104 \\
\hline No & $90 / 875(10.3)$ & Reference & & & \\
\hline Yes & $25 / 168(14.9)$ & $1.525(0.946,2.458)$ & 0.083 & & \\
\hline \multicolumn{6}{|l|}{ Missing } \\
\hline \multicolumn{4}{|c|}{ Sedation used } & 0.002 & 0.002 \\
\hline No & $20 / 326(6.1)$ & Reference & & & \\
\hline Yes & $103 / 816(12.6)$ & $2.210(1.344,3.634)$ & 0.002 & & \\
\hline Missing & 8 & & & & \\
\hline
\end{tabular}

The reason for performing a screening procedure had an effect on WT $(p=0.005)$ with 'Following positive screening test' associated with a longer mean WT ( $9.3 \pm 3.3 \mathrm{~min})$ than either 'Screening due to familial risk' $(7.9 \pm 3.0 \mathrm{~min})$ or 'Screening without pre-screening test' $(8.1 \pm 4.4 \mathrm{~min})$. This difference was also apparent in the proportions receiving WTs of less than $6 \mathrm{~min}(4.3 \%$ vs. $17.5 \%$ and $16.2 \%$, respectively, $p=0.008)$, and the trend was apparent, but not statistically significant, in the proportion greater than $10 \mathrm{~min}(19.8 \%$ vs. $11.9 \%$ and $14.9 \%$, respectively, $p=0.232$ ).

We performed analysis of the effect of an abnormal endoscopic finding on WT to examine whether the reason for short WTs was the discovery of pathology (noting that procedures involving endoscopic intervention were excluded from WT analysis). Abnormal endoscopic finding had no association with mean WT: yes $8.0 \pm 3.5 \mathrm{~min}(\mathrm{n}=461)$ vs. no $7.7 \pm 2.8 \mathrm{~min}(\mathrm{n}=681)(p=0.112)$. There was also no effect on the proportion of patients with a WT less than 6 min: yes $14.1 \%(65 / 461)$ vs. no $12.5 \%(85 / 681)(p=0.427)$. However, there was an increase in the proportion of those with a WT over $10 \mathrm{~min}$ for those with an abnormal endoscopic finding: yes $12.8 \%$ (59/461) vs. no $9.0 \%$ (61/681); OR $1.492,95 \% \mathrm{CI}$ $1.021,2.180(p=0.039)$. Abnormal endoscopic findings included cancer $(\mathrm{n}=19)$, diverticula $(n=322)$, inflammation $(n=46)$, polyps $(n=52)$, hemorrhoids $(n=44)$, and other findings $(\mathrm{n}=40)$.

An analysis was conducted to see if any particular variable interacted with the effect of time of day the colonoscopy was performed on the length of WT. This analysis was restricted to 850 procedures, with responses to 'Time of colonoscopy' that could not clearly be assigned to a time of day category being excluded. The reason for procedure (diagnostic vs. screening) was the only variable found to significantly interact with the WT, both mean WT $(p=0.005)$ and the proportion with a WT under $6 \mathrm{~min}(p=0.015)$, but not the proportion over $10 \mathrm{~min}(p=0.420)$. See Figure 3 for how time colonoscopy was performed influences the proportion with a WT of less than 6 min according to the reason for the procedure. 


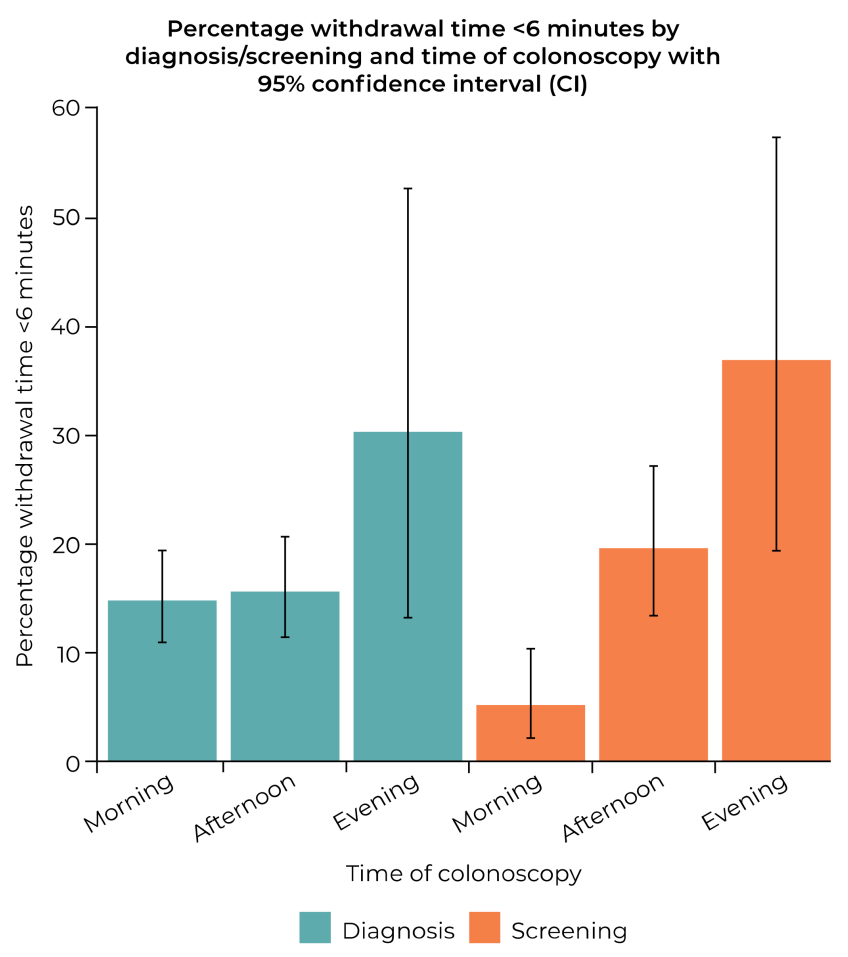

Figure 3. Influence of time colonoscopy was performed on the proportion of procedures with withdrawal time $<6 \mathrm{~min}$ according to reason for procedure being diagnosis or screening.

\subsection{Impact of Sedation}

The type of sedation used had a significant association with mean WT $(p<0.001)$ (Figure 4). In particular, the proportion of patients with a WT of $>10$ min was substantially greater with midazolam used in combination with propofol, and to a lesser extent, but still significant, with the use of midazolam and opioid together, nitrous oxide alone, and propofol alone (Table 3).

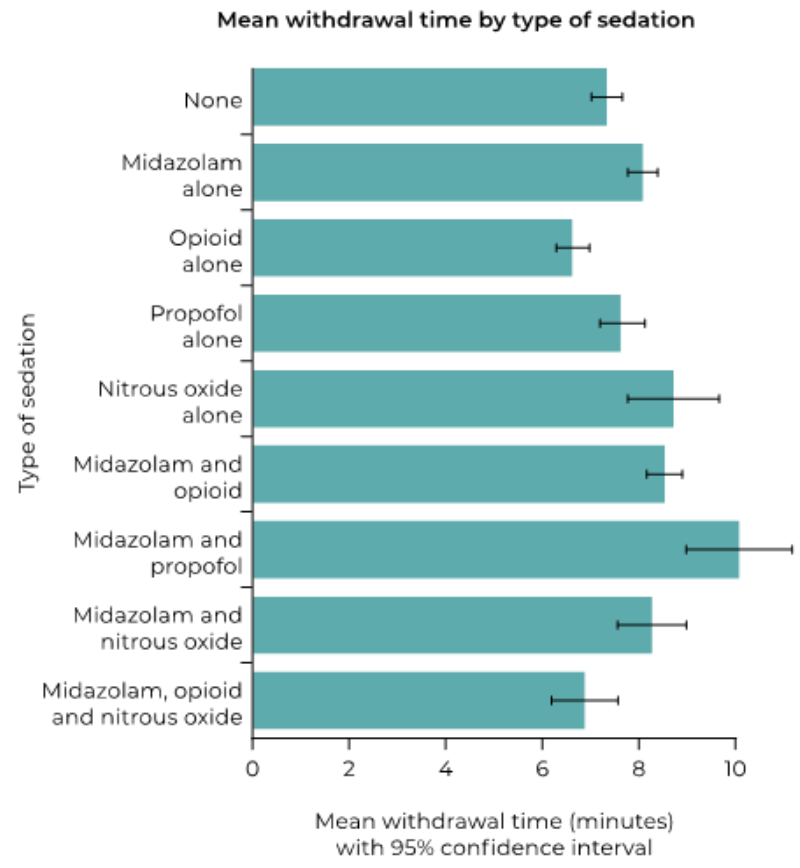

Figure 4. Mean withdrawal time (minutes) according to type of sedation used. 
Table 3. Proportion of procedures with a withdrawal time greater than $10 \mathrm{~min}$ according to type of sedation (combinations with a frequency $<10$ were excluded from analysis).

\begin{tabular}{cccc}
\hline & Proportion with Withdrawal Time $>\mathbf{1 0}$ min (\%) & Odds Ratio (95\%CI) & $p$ Value \\
\hline Type of sedation & & $<.001$ \\
None & $20 / 326(6.1)$ & Reference & $0.312(0.072,1.360)$ \\
Midazolam alone & $2 / 100(2.0)$ & $0.494(0.112,2.166)$ & 0.349 \\
Opioid alone & $2 / 64(3.1)$ & $1.893(1.018,3.519)$ & 0.044 \\
Propofol alone & $24 / 218(11.0)$ & $2.700(1.015,7.185)$ & 0.047 \\
Nitrous oxide alone & $6 / 40(15.0)$ & $3.140(1.835,5.374)$ & $<0.001$ \\
Midazolam and opioid & $55 / 323(17.0)$ & $8.345(3.616,19.259)$ & $<0.001$ \\
Midazolam and propofol & $12 / 34(35.3)$ & 0 & - \\
Midazolam and nitrous oxide & $0 / 11(0)$ & 0 & - \\
Midazolam, opioid, and nitrous oxide & $0 / 15(0)$ & & 0 \\
\hline
\end{tabular}

\section{Discussion}

The ESGE recommends that the mean WT is at least 6 min with a target standard of $10 \mathrm{~min}$ [1]. We found a mean WT in qualifying colonoscopies of $7.8 \mathrm{~min}$. A WT over 10 min occurred in only $10.8 \%$ of procedures, while a WT under 6 min occurred in $13.0 \%$ of procedures.

In analysis of known data, the main factors associated with mean WT were whether the patient had a previous colonoscopy within the past five years and the time of day that the colonoscopy was performed. The main factor associated with a WT of less than 6 min was the time of day the colonoscopy was performed. The use of sedation was the main factor associated with a higher proportion of WTs over $10 \mathrm{~min}$, along with a previous colonoscopy.

Our known data analysis found a significant association between the time of day that a colonoscopy is performed and mean WT, with lower times later in the day, culminating in an increased proportion with a WT less than $6 \mathrm{~min}$. This finding is in agreement with Marcondes et al., who found a roughly $20 \%$ reduction in WT from the first to last colonoscopy of the day [8]. A decline in ADR and PDR was also apparent in colonoscopies performed later in the clinic schedule. Teng et al. also found a reduction in WT from morning to afternoon sessions. Indeed, along with increasing patient age, WT was found to be a significant predictor of decline in ADR from morning to afternoon sessions. Furthermore, after controlling for WT and advancing age, the difference in ADR between morning and afternoon was no longer significant. [9] Both papers conclude that the most likely reason for the reduction in WT is rushing procedures later in the day $[8,9]$.

The ESGE states that colonoscopy needs adequate time allocated for the entire procedure (including discussion with the patient, sedation, insertion, withdrawal, and therapy) [1]. Time pressure due to inadequate time slots may impair colonoscopy quality. A minimum standard of $30 \mathrm{~min}$ for a clinical and primary screening colonoscopy, and $45 \mathrm{~min}$ for a colonoscopy following positive fecal occult blood testing is recommended. Our findings of an association between time of day and WT could be indicative of insufficient time allotted to procedures leading to 'rushing' of procedures towards the end of clinic time.

Further to the findings of Singh et al. that a difference in ADR between morning and afternoon colonoscopies was mainly found in female patients [10], we looked at whether any of our variables interacted with the relationship between WT and the time that the colonoscopy was performed. We found no effect of gender on WT. However, we found that the factor significantly associated with the increase in proportion of patients with a WT $<6$ min according to time of day was screening being the reason for procedure. This suggests that screening patients, in particular, are more likely to receive shorter WTs later in the day.

Evidently, shortening WTs in screening patients can have negative consequences. Kumar et al. showed that a WT of 3 min was associated with a substantial increase in the adenoma miss rate compared with a WT of $6 \min (48.0 \%$ vs. $22.9 \%, p=0.0001)$ [11] 
When identifying incident interval cancers via cancer registry linkages that were diagnosed within 5.5 years after the screening examination, Shaukat et al. found that physicians' mean annual WTs were inversely associated with cancer incidence $(p<0.0001)$. Compared with WTs $\geq 6 \mathrm{~min}$, the adjusted incidence rate ratio for WTs of $<6$ min was 2.3 (95\% CI: 1.5, 3.4; $p<0.0001)$ [12].

The ESGE recommend the measurement of WT when ADR is below the minimum standard of $25 \%$ [1]. Our findings indicate that WT is an important factor in screening and diagnostic colonoscopies. It is also a factor that is potentially under colonoscopist control [13]. Encouraging longer WTs by allowing sufficient appointment time, and possibly using interventions to encourage achievement of higher mean WTs, has the potential to improve polyp detection [14-19]. Indeed, simply being aware that WT is being monitored has been shown to provide improvement [20-22].

The use of sedation was significantly associated with mean WT and was a key factor associated with WTs $>10 \mathrm{~min}$. An international expert panel agreed that patients undergoing colonoscopy should be offered the choice of sedation or no sedation [23]. The majority of procedures in our dataset were performed with some form of sedation administered: $71.5 \%$ of the WT analysis.

Propofol for sedation during colonoscopy for generally healthy individuals can lead to faster recovery and discharge times, as well as increased patient satisfaction without an increase in complications [24]. However, there is still debate over whether it is appropriate for propofol to be administered without the presence of an anesthesiologist [25,26].

Analyses have demonstrated that administration of propofol by an endoscopist or specialist nurse is safe and effective [27-29]. Patient satisfaction has also been shown to be better with the use of propofol compared with a combination of midazolam and opioid [28,30]. However, the use of propofol vs. midazolam plus opioid does not necessarily lead to an increase in ADR/PDR or WT [31-33].

\subsection{Multiple Imputation Analysis}

MI was used as a sensitivity analysis. The main causes of missing data for the stepwise models were the time of day that the colonoscopy was performed and the BMI category. The proportions for the observed and imputed data for each of these variables were reasonably matched. The univariate results using the MI and observed data were broadly in agreement, although the significance of the time of day that the colonoscopy was performed was lost for WT itself. This could reflect an inherent problem with imputing the time of day the colonoscopy was performed, since these data may not be missing at random. For example, some clinics might only perform colonoscopies in the morning.

With the MI data, differences were found for the stepwise models. First, gender in addition to time of day was included in each of the 100 stepwise models for the proportion of procedures with WT of less than $6 \mathrm{~min}$. Second, for the proportion of procedures with WT greater than $10 \mathrm{~min}$, patient type, reason for procedure, and adequate cleansing, rather than a total colonoscopy within the last five years, were the most important factors together with sedation (each was included in each of the 100 models). Third, for the WT, adequate cleansing, sedation, patient type, and reason for procedure were included in each of the 100 models, while time of day and total colonoscopy within the last five years were included in 76 and 10 models, respectively.

Thus, while no clarity was provided by MI on the most important factors influencing WT overall, the time of day that the colonoscopy was performed and sedation use were confirmed as highly influential factors for WT less than 6 min and greater than $10 \mathrm{~min}$, respectively.

\subsection{Limitations}

The publication of the ESGE performance measures occurred after this version of the questionnaire was compiled, therefore there are some areas where our measures do not exactly match those specified by the ESGE. Some issues with the completion of the 
questionnaire were also identified, which have led to some responses being excluded from analysis due to either incorrect interpretation of the question or implausible responses. This has restricted the number of procedures that could be included in the multivariable analyses. In future, with a revised questionnaire design, we should be able to substantially reduce the number of non-eligible responses, which should improve the power of the analysis.

The institutions and practitioners completing this questionnaire are from a range of countries across Europe. While this is a strength in that it provides a variety of practices enabling the assessment of a wide range of variables to see which influence outcomes, it also means that the practices in some countries may be overrepresented and could skew results. Selection bias is also possible, as we have no control over which procedures practitioners choose to document. Additional variables that could have influenced the results include the day of the week that the colonoscopy was performed and the level of experience of the colonoscopist. These variables could be included in future questionnaires/analyses.

This analysis was exploratory in nature and guided by findings from these data. The observations would ideally be confirmed by prospective studies, for example by using training and validation subsets.

\section{Conclusions}

On average, the sample of European practice captured by the ECQI survey meets the minimum standards set by the ESGE. However, there is variation and potential for improvement. In particular, educational initiatives regarding the importance of maintaining WTs throughout the day, particularly in screening patients, could yield benefits in terms of cancer detection. The use of sedation has the potential to improve WTs and, in accordance with local protocols, should be offered to all patients undergoing colonoscopy.

Supplementary Materials: The following is available online at https: / /www.mdpi.com/article / 10.3390/diagnostics12020503/s1, ECQI Procedure Questionnaire.

Author Contributions: Contributions to the design of the survey, C.S., P.A., A.A., L.B., W.F., M.H., R.J., A.O., L.P., J.F.R., E.T. and A.L.S.; contributions to the acquisition of the data, C.S., P.A., A.A., L.B., W.F., M.H., R.J., U.K., A.O., Á.P., S.P., J.F.R. and E.T.; Analysis and interpretation of data, H.S., A.L.S., A.K., E.T., P.A., L.F., C.H. and G.A.; Writing-original draft preparation, A.L.S.; Revising critically for important intellectual content, all authors. All authors have read and agreed to the published version of the manuscript.

Funding: Funding from Norgine Ltd. was received by Aspen Medical Media for provision of ECQI Secretarial support and by Pharmatelligence, for management of the questionnaire database.

Institutional Review Board Statement: This survey was performed with anonymized data, collected during regular clinical care, representing an audit of routine endoscopic practice against quality standards. Accordingly, participating physicians were encouraged to follow relevant local regulations. Furthermore, contemporary (pre-General Data Protection Regulation, GDPR, 2018) guidance was followed at the time of data collection.

Informed Consent Statement: This survey was performed with anonymized data, collected during regular clinical care, representing an audit of routine endoscopic practice against quality standards. Accordingly, participating physicians were encouraged to follow relevant local regulations. Furthermore, contemporary (pre-General Data Protection Regulation, GDPR, 2018) guidance was followed at the time of data collection. Informed consent, where applicable was obtained.

Data Availability Statement: An application form to access the data is available from the ECQI Secretariat upon receipt of a rationale and statistical analysis plan.

Acknowledgments: The ECQI Group is grateful for the continued financial support provided by Norgine Ltd. In October 2016, the ECQI Group became an independent working party, free to obtain funding from any reputable source. The authors greatly acknowledge the support from Bharat Amlani (employee of Norgine). Whilst it is not possible to acknowledge everyone individually, we are indebted and grateful to all of those who took the time to complete our questionnaires and provide an insight into their real-world practice. We would like to thank the practitioners who 
contributed to the ECQI dataset from the following institutions. In Belarus: the NN Alexandrov National Cancer Centre of Belarus; in Denmark: Herlev Hospital, Kirurgisk Klinik Frederikssund, Kirurgisk Klinik Syddanmark, Odense University Hospital Svendborg Sygehus; in Finland: Tampere University Hospital; in Germany: Allgemeines Krankenhaus Celle AKH, Gemeinschaftspraxis für Gastroenterologie und Innere Medizin Aschaffenburg, Internisten am Dominikanerplatz Würzburg, Klinikum Aschaffen-burg-Alzenau, Mathias-Spital Rheine, Sankt Elisabeth Hospital Gütersloh; in Hungary: Markusovszky University Teaching Hospital, University of Pécs, University of Szeged; in Italy: Centro di Riferimento Oncologico IRCCS, CTO and Sirai Hospitals Sardinia, Fondazione Poliambulanza Brescia, Fondazione Policlinico Gemelli Rome, Policlinico Umberto I "Sapienza" University of Rome; in Portugal: Centro Hospitalar do Baixo Vouga Aveiro, Centro Hospitalar Tondela-Viseu, Centro Hospitalar e Universitário de Coimbra, Endocentro-Idealmed UHC Coimbra, Portuguese Oncology Institute Coimbra, ULS Guarda; in Romania: Gastroenterology and Hepatology Center-TVM-Cluj-Napoca, Octavian Fodor Regional Institute of Gastroenterology and Hepatology, Research Center of Gastroenterology and Hepatology University of Medicine and Pharmacy of Craiova; in Russia: Yaroslavl Regional Cancer Hospital; in Spain: Hospital Álvaro Cunqueiro Vigo, Hospital Clínico Universitario Virgen de la Arrixaca, Hospital General Universitario de Alicante, Hospital del Mar Barcelona, Hospital Nisa Sevilla Aljarafe, Hospital Universitario de Fuenlabrada, Hospital Universitario Central de Asturias, Hospital Universitari i Politècnic La Fe Valencia; in Sweden: Ängelholm Hospital, Blekinge Hospital Karlshamn-Karlskrona, Capio St Göran's Hospital Stockholm, Central Hospital Karlstad, Centralsjukhuset Kristianstad, GHP Stockholm Gastro Center, Helsingborg Hospital, Institute of Medicine Huddinge Karolinska Hospital Stockholm, Karolinska University Hospital Stockholm, Skåne University Hospital Malmö, South Älvsborg Hospital Borås, Specialistläkarna i Lund, Sunderby Hospital Luleå, University Hospital Linköping, Ystad Hospital; in the United Kingdom: Barnsley District General Hospital, Doncaster Royal Infirmary, Mid Yorkshire NHS Trust Grange Medical Centre, Royal Liverpool and Broadgreen University Hospitals, The Royal Infirmary of Edinburgh.

Conflicts of Interest: C.S. is a consultant and advisory board participant for Norgine, AlfaSigma, Medtronic, Given Imaging, Covidien, Olympus, IntroMedic, AnX Robotica. A.K. reports material support from IntroMedic/SynMedUK, Jinshan/Aquilant; honoraria from Ferring UK, Dr Falk Pharma UK; travel support from Norgine, Jinshan/Aquilant; advisory board Dr Falk Pharma UK, Tillots; Given ${ }^{\circledR}$ Imaging Ltd. / ESGE research grant 2011; cofounder AJM Med-i-caps Ltd, director of iCERV LTD and consultant for Jinshan (since March 2021). P.A. reports consultancy and advisory board participant for Norgine. L.B. reports consultancy \& advisory board participant AMBU; travel support from Norgine. W.F. reports consultancy and advisory board participant to Norgine; speaking-Abbott, Bio Merieux, Falk; advisory speaking-Aptalis, Fresenius Biotech, Pfizer; advisory-Boehringer Ingelheim, med update. M.H. reports travel support from Norgine. R.J. reports consultancyNorgine, MSD, GI Supply, CPP Pharma. U.K. reports travel support from Norgine. A.O. reports travel support from Norgine. E.T. reports consultancy and advisory board participant for Norgine. A.A., Á.P., S.P., L.P., J.F.R., L.F., G.A. \& C.H. declare that they have no conflict of interest. H.S. received fees for statistical services and A.L.S. received fees for manuscript preparation from the ECQI Secretariat. The funder does not have direct access to the data. The funder had limited input into the design of the survey. The funder had no role in the collection, analyses, or interpretation of data, in the writing of the manuscript, or in the decision to publish the results.

\section{References}

1. Kaminski, M.F.; Thomas-Gibson, S.; Bugajski, M.; Bretthauer, M.; Rees, C.J.; Dekker, E.; Hoff, G.; Jover, R.; Suchanek, S.; Ferlitsch, M.; et al. Performance measures for lower gastrointestinal endoscopy: A European Society of Gastrointestinal Endoscopy (ESGE) quality improvement initiative. United Eur. Gastroenterol. J. 2017, 5, 309-334. [CrossRef]

2. Spada, C.; Koulaouzidis, A.; Hassan, C.; Amaro, P.; Agrawal, A.; Brink, L.; Fischbach, W.; Hünger, M.; Jover, R.; Kinnunen, U.; et al. Colonoscopy quality across Europe: A report of the European Colonoscopy Quality Investigation (ECQI) Group. Endosc. Int. Open 2021, 9, e1456-e1462. [CrossRef] [PubMed]

3. Rembacken, B.; Hassan, C.; Riemann, J.F.; Chilton, A.; Rutter, M.; Dumonceau, J.M.; Omar, M.; Ponchon, T. Quality in screening colonoscopy: Position statement of the European Society of Gastrointestinal Endoscopy (ESGE). Endoscopy 2012, 44, 957-968. [CrossRef] [PubMed]

4. Riemann, J.F.; Agrawal, A.; Amaro, P.; Brink, L.; Fischbach, W.; Hünger, M.; Jover, R.; Ono, A.; Toth, E.; Spada, C. Adoption of colonoscopy quality measures across Europe: The European Colonoscopy Quality Investigation (ECQI) Group experience. United Eur. Gastroenterol. J. 2018, 6, 1106-1107. [CrossRef] [PubMed] 
5. Calderwood, A.H.; Jacobson, B.C. Comprehensive validation of the Boston Bowel Preparation Scale. Gastrointest. Endosc. 2010, 72, 686-692. [CrossRef]

6. Azur, M.J.; Stuart, E.A.; Frangakis, C.; Leaf, P.J. Multiple imputation by chained equations: What is it and how does it work? Int. J. Methods Psychiatr. Res. 2011, 20, 40-49. [CrossRef]

7. Rubin, D.B. Multiple Imputation for Nonresponse in Surveys; John Wiley \& Sons: New York, NY, USA, 1987.

8. Marcondes, F.O.; Gourevitch, R.A.; Schoen, R.E.; Crockett, S.D.; Morris, M.; Mehrotra, A. Adenoma Detection Rate Falls at the End of the Day in a Large Multi-site Sample. Dig. Dis. Sci. 2018, 63, 856-859. [CrossRef]

9. Teng, T.Y.; Khor, S.N.; Kailasam, M.; Cheah, W.K.; Lau, C.C. Morning colonoscopies are associated with improved adenoma detection rates. Surg. Endosc. 2016, 30, 1796-1803. [CrossRef]

10. Singh, S.; Dhawan, M.; Chowdhry, M.; Babich, M.; Aoun, E. Differences between morning and afternoon colonoscopies for adenoma detection in female and male patients. Ann. Gastroenterol. 2016, 29, 497-501. [CrossRef]

11. Kumar, S.; Thosani, N.; Ladabaum, U.; Friedland, S.; Chen, A.M.; Kochar, R.; Banerjee, S. Adenoma miss rates associated with a 3-minute versus 6-minute colonoscopy withdrawal time: A prospective, randomized trial. Gastrointest. Endosc. 2017, 85, 1273-1280. [CrossRef]

12. Shaukat, A.; Rector, T.S.; Church, T.R.; Lederle, F.A.; Kim, A.S.; Rank, J.M.; Allen, J.I. Longer Withdrawal Time Is Associated With a Reduced Incidence of Interval Cancer After Screening Colonoscopy. Gastroenterology 2015, 149, 952-957. [CrossRef] [PubMed]

13. Jover, R.; Zapater, P.; Polanía, E.; Bujanda, L.; Lanas, A.; Hermo, J.A.; Cubiella, J.; Ono, A.; González-Méndez, Y.; Peris, A.; et al. Modifiable endoscopic factors that influence the adenoma detection rate in colorectal cancer screening colonoscopies. Gastrointest. Endosc. 2013, 77, 381-389.e1. [CrossRef] [PubMed]

14. Barclay, R.L.; Vicari, J.J.; Greenlaw, R.L. Effect of a time-dependent colonoscopic withdrawal protocol on adenoma detection during screening colonoscopy. Clin. Gastroenterol. Hepatol. 2008, 6, 1091-1098. [CrossRef] [PubMed]

15. Nielsen, A.B.; Nielsen, O.H.; Hendel, J. Impact of feedback and monitoring on colonoscopy withdrawal times and polyp detection rates. BMJ Open. Gastroenterol. 2017, 4, e000142. [CrossRef]

16. Then, E.O.; Brana, C.; Dadana, S.; Maddika, S.; Ofosu, A.; Brana, S.; Wexler, T.; Sunkara, T.; Culliford, A.; Gaduputi, V. Implementing visual cues to improve the efficacy of screening colonoscopy: Exploiting the Hawthorne effect. Ann. Gastroenterol. 2020, 33, 374-378. [CrossRef]

17. Ishibashi, F.; Fukushima, K.; Kobayashi, K.; Kawakami, T.; Tanaka, R.; Kato, J.; Sato, A.; Konda, K.; Sugihara, K.; Baba, S. Individual feedback and monitoring of endoscopist performance improves the adenoma detection rate in screening colonoscopy: A prospective case-control study. Surg. Endosc. 2021, 35, 2566-2575. [CrossRef]

18. Su, J.R.; Li, Z.; Shao, X.J.; Ji, C.R.; Ji, R.; Zhou, R.C.; Li, G.C.; Liu, G.Q.; He, Y.S.; Zuo, X.L.; et al. Impact of a real-time automatic quality control system on colorectal polyp and adenoma detection: A prospective randomized controlled study (with videos) Gastrointest. Endosc. 2020, 91, 415-424.e4. [CrossRef]

19. Zhao, S.; Yang, X.; Wang, S.; Meng, Q.; Wang, R.; Bo, L.; Chang, X.; Pan, P.; Xia, T.; Yang, F.; et al. Impact of 9-Minute Withdrawal Time on the Adenoma Detection Rate: A Multicenter Randomized Controlled Trial. Clin. Gastroenterol. Hepatol. 2020, 20, e168-e181. [CrossRef]

20. Manes, G.; Andreozzi, P.; Omazzi, B.; Bezzio, C.; Redaelli, D.; Devani, M.; Morganti, D.; Reati, R.; Saibeni, S.; Mandelli, E.; et al Efficacy of withdrawal time monitoring in adenoma detection with or without the aid of a full-spectrum scope. Endosc. Int. Open 2019, 7, E1135-E1142. [CrossRef]

21. Vavricka, S.R.; Sulz, M.C.; Degen, L.; Rechner, R.; Manz, M.; Biedermann, L.; Beglinger, C.; Peter, S.; Safroneeva, E.; Rogler, G.; et al Monitoring colonoscopy withdrawal time significantly improves the adenoma detection rate and the performance of endoscopists. Endoscopy 2016, 48, 256-262. [CrossRef]

22. Parihar, V.; O'Leary, C.; O'Reagan, P. Timed colonoscopy withdrawal, a mandatory quality measure in the era of national screening? Ir. J. Med. Sci. 2018, 187, 943-945. [CrossRef] [PubMed]

23. Cohen, L.B.; Ladas, S.D.; Vargo, J.J.; Paspatis, G.A.; Bjorkman, D.J.; Van der Linden, P.; Axon, A.T.; Axon, A.E.; Bamias, G.; Despott, E.; et al. Sedation in digestive endoscopy: The Athens international position statements. Aliment. Pharmacol. Ther. 2010, 32, 425-442. [CrossRef] [PubMed]

24. Singh, H.; Poluha, W.; Cheung, M.; Choptain, N.; Baron, K.I.; Taback, S.P. Propofol for sedation during colonoscopy. Cochrane Database Syst. Rev. 2008, 4, CD006268. [CrossRef] [PubMed]

25. Lin, O.S. Sedation for routine gastrointestinal endoscopic procedures: A review on efficacy, safety, efficiency, cost and satisfaction. Intest. Res. 2017, 15, 456-466. [CrossRef] [PubMed]

26. Triantafillidis, J.K.; Merikas, E.; Nikolakis, D.; Papalois, A.E. Sedation in gastrointestinal endoscopy: Current issues. World J. Gastroenterol. 2013, 19, 463-481. [CrossRef] [PubMed]

27. Gouda, B.; Gouda, G.; Borle, A.; Singh, A.; Sinha, A.; Singh, P.M. Safety of non-anesthesia provider administered propofol sedation in non-advanced gastrointestinal endoscopic procedures: A meta-analysis. Saudi J. Gastroenterol. 2017, 23, 133-143. [CrossRef] [PubMed]

28. Zhang, W.; Zhu, Z.; Zheng, Y. Effect and safety of propofol for sedation during colonoscopy: A meta-analysis. J. Clin. Anesth. 2018, 51, 10-18. [CrossRef] 
29. Rex, D.K.; Deenadayalu, V.P.; Eid, E.; Imperiale, T.F.; Walker, J.A.; Sandhu, K.; Clarke, A.C.; Hillman, L.C.; Horiuchi, A.; Cohen, L.B.; et al. Endoscopist-directed administration of propofol: A worldwide safety experience. Gastroenterology 2009, 137, 1229-1237. [CrossRef]

30. Padmanabhan, A.; Frangopoulos, C.; Shaffer, L.E.T. Patient Satisfaction With Propofol for Outpatient Colonoscopy: A Prospective, Randomized, Double-Blind Study. Dis. Colon Rectum 2017, 60, 1102-1108. [CrossRef]

31. Nakshabendi, R.; Berry, A.C.; Munoz, J.C.; John, B.K. Choice of sedation and its impact on adenoma detection rate in screening colonoscopies. Ann. Gastroenterol. 2016, 29, 50-55.

32. Wang, A.; Hoda, K.M.; Holub, J.L.; Eisen, G.M. Does level of sedation impact detection of advanced neoplasia? Dig. Dis. Sci. 2010, 55, 2337-2343. [CrossRef] [PubMed]

33. Thirumurthi, S.; Raju, G.S.; Pande, M.; Ruiz, J.; Carlson, R.; Hagan, K.B.; Lee, J.H.; Ross, W.A. Does deep sedation with propofol affect adenoma detection rates in average risk screening colonoscopy exams? World J. Gastrointest. Endosc. 2017, 9, 177-182. [CrossRef] [PubMed] 